Check for updates

Cite this: RSC Adv., 2018, 8, 22670

\title{
Hydrolysis dynamics for batch anaerobic digestion of elephant grass
}

\author{
Gaixiu Yang, Yongming Sun, Lianhua Li, Pengmei Lv, (D) Xiaoying Kong iD \\ and Dalong Huang $1 D$
}

Elephant grass might be a potential source of fine chemical precursors and bioenergy. In the present study, we investigated the dynamics of hydrolysis of elephant grass. Three models were used to fit the hydrolysis rate constants-flat, spherical, and cylindrical models. The hydrolysis rate constants obtained using the spherical model presented the best fit between the experimental and theoretical values. Furthermore, we determined the secondary reinforcement points and interventions that can be introduced to speed up the hydrolysis process. Our findings will provide information for studies on the hydrolysis of elephant grass and promote its application in the biogas industry as an alternative biofuel.

Received 5th February 2018

Accepted 11th June 2018

DOI: $10.1039 / c 8 r a 01115 j$

rsc.li/rsc-advances
Furthermore, due to its short agricultural cycle, the grass can be harvested five to six times per year. ${ }^{9}$ Currently, elephant grass is grown widely in Hainan, Guangdong, Guangxi, Hunan, Sichuan, and Yunnan Provinces of China. Except for being used as animal fodder, it is also a potential source of bioenergy owing to its high growth potential and stem with solid center, similar to that in maize, corn stover ${ }^{10}$ and sugar cane. All of this makes elephant grass becomes a promising source of lignocellulosic biomass due to its high growth potential, biomass yield, limited requirement for cultivation land and high rates of carbon dioxide absorption.

Anaerobic digestion (AD) technology is an efficient method to obtain energy from crops. The $\mathrm{CH}_{4}$-rich biogas produced is suitable for energy and can alleviate the excessive use of fossil fuels. As part of an integrated waste management system, AD contributes to the mitigation of greenhouse gas emission by reducing methane emission that occurs when waste materials are dumped in landfills. Thus, AD provides an efficient way to utilize energy grass. In the US and Europe, energy crops such as switchgrass, miscanthus and reed canary grass, have been used as feedstock for AD since the mid-1980s. ${ }^{11-13}$ In China, vetiver grass, smooth cordgrass, and comfrey are the main energy grasses that have been used for AD. ${ }^{14}$

It is known that $\mathrm{AD}$ can be described as a sequential process that involves the following steps: hydrolysis, acidogenesis, acetogenesis, and methanogenesis. Hydrolysis is known to be a critical process-(rate-determining step) of $\mathrm{AD}$, resulting in a low methane production when complex substrates, such as lignocellulosic materials, are used as feedstocks. ${ }^{15}$

The rigid structure of elephant grass limits its utilization by microbes ${ }^{16}$ which significantly restricts the biogas production efficiency of energy grass. Pretreatment is an essential part for improving the hydrolysis efficiency, which has been the deemed as an effective method to improve the lignocellulose digestion
Guangzhou Institute of Energy Conversion, Key Laboratory of Renewable Energy, Guangdong Key Laboratory of New and Renewable Energy Research and Development, Chinese Academy of Sciences, Guangzhou 510640, China. E-mail: huangdl@ms.giec.ac.cn 
efficiency and biogas production by breaking the lignin seal, disrupting the crystalline structure of cellulose, and making cellulose more accessible to the enzymes or microbes. However, it is difficult to accurately determine the pretreatment parameters just through experiments. Thus, it is necessary to introduce modified kinetics models that elucidate the hydrolysis of elephant grass, which will improve the digestion efficiency and biogas production.

Several models are mainly being used to describe the hydrolysis kinetics of organic material, such as first-order, Contois and Monod, which are then combined to form mechanistic models. A typical hydrolysis kinetics is considerably complex and have many limitations, as mentioned by Borja ${ }^{17}$ and Valentini. ${ }^{18}$ For instance, the Monod equation can be used to describe the hydrolysis process of soluble organic particles; however, it is not applicable for particulate organic matter. $\mathrm{Hu}$ et $a .^{19}$ indicated that the Contois equation is more suitable to describe the kinetics of pilot-scale processes than the Monod equation.

The first-order kinetics presents a good application in modeling the hydrolysis process of particulate organic matter. However, for complex substrates, the first-order kinetics should be modified to account for the hardly degradable material. Vavilin et al. developed a model that incorporated the colonization of cellulose particles by a pre-existing cellulose-bound bacterial population, with the associated progressive reduction in particle size due to cellulose hydrolysis. The model assumed that the pre-existing cellulose-bound biomass population is solely responsible for particle colonization. ${ }^{20}$ Rotter et al. developed a new model to simulate cellulose hydrolysis, which uniquely incorporated the ability of free-floating bacteria to colonize cellulose particles by attachment through contact in solution. ${ }^{21}$ For further optimization of anaerobic digestion, Biernacki et al. analyzed biogas production with commonly used substrates, including grass, maize, and green weed silage, together with industrial glycerine by Weender analysis/van Soest method, and a simulation study was conducted, based on the International Water Association's (IWA) Anaerobic Digestion Model No. 1 (ADM1). The optimization led to a precise prediction of kinetics of anaerobic degradation of complex substrates. ${ }^{22}$ Currently, the hydrolysis kinetic models for elephant grass have not been well studied. Therefore, establishing hydrolysis kinetic models for elephant grass is essential, considering its importance in bioenergy production.

In the present study, the hydrolysis kinetics of perennial elephant grass grown in South China was investigated. In order to avoid the inevitable loss of easily hydrolyzed and degraded sugars and hemicellulose and the production of fermentation inhibitors (such as furfural, fatty acids and aromatic compounds), the degradation rule of the substrate was studied by the introduction of modified hydrolysis kinetic models. Three models-flat, spherical, and cylindrical models-were used to fit the hydrolysis rate constants. The spherical model exhibited the best fit between experimental and theoretical values. Furthermore, to speed up the hydrolysis reaction, the secondary reinforcement points that can be intervened were determined. The findings of the present study might promote the use of energy grass in biogas industry.

\section{Materials and methods}

\subsection{Characteristics of feedstock}

Perennial elephant grass was manually harvested from a field in the north campus of South China University of Technology, Guangzhou, China. The raw material mainly contained cellulose $(29.27 \%)$, hemicellulose (26.61\%), and lignin (17.99\%). The content of total solid (TS) and volatile solid (VS) of the feedstock was $15.16 \%$ and $12.81 \%$, respectively, and the ratio of VS/TS was 0.85 , indicating that the digestible content in the feedstock was very high. The mass fraction of $\mathrm{C}$ and $\mathrm{N}$ elements was $40.94 \%$ and $0.737 \%$, respectively, and the ratio of $\mathrm{C} / \mathrm{N}$ was 55.55 . The optimum range of $\mathrm{C} / \mathrm{N}$ ratio for anaerobic fermentation is 2532. The acidification of anaerobic fermentation occurs at a high ratio of $\mathrm{C} / \mathrm{N}$ and is restrained by ammonia nitrogen when the ratio of $\mathrm{C} / \mathrm{N}$ is too low. Hence, the addition of appropriate amount of ammonium bicarbonate to the fermentation broth enables the adjustment of this ratio. The calorific value of the feedstock was $16566.2 \mathrm{~kJ} \mathrm{~kg}^{-1}$.

\subsection{Inoculated sludge}

The inoculum, sieved through a $1 \mathrm{~mm}$ mesh to remove large particles, was obtained from a mesophilic anaerobic digestion reactor fed with swine manure (Boluo, Guangdong, China). The $\mathrm{pH}$, TS content, and VS content of the inoculum were 7.30, $3.59 \%$, and $2.32 \%$, respectively.

\subsection{Experimental setup and procedure}

The experiment was performed in batches in $500 \mathrm{~mL}$ glass bottles at $310 \mathrm{~K}$ in a thermostatic water bath in duplicates. The digesters were flushed with $\mathrm{N}_{2}$ gas for $3 \mathrm{~min}$ to remove oxygen. All the bottles were then sealed with butyl rubber stoppers attached to exhaust pipes, and the air outlets were sealed with water. All the bottles were filled with $300 \mathrm{~g}$ of inoculum and $100 \mathrm{~g}$ of crushed feedstock; $2.5 \%$ ammonium bicarbonate was added to improve the buffer capacity, which also served as a supplementary nitrogen source. During the experiment, all the reactors were manually shaken twice a day. The experiments were conducted for over $20 \mathrm{~d}$.

\subsection{Analysis methods}

The content of $\mathrm{C}, \mathrm{N}, \mathrm{H}$, and $\mathrm{S}$ was measured using a Vario EL elemental analyzer (Elementar Corporation, Germany). The compositional analysis was carried out following the procedure described by the National Renewable Energy Laboratory (NREL). ${ }^{23}$ The HPLC system (Waters 2698, USA) equipped with a sugar column (SH1011, Shodex) was used to measure the sugar concentration at $323 \mathrm{~K}$ with $5 \mathrm{mM} \mathrm{H}_{2} \mathrm{SO}_{4}$ as the mobile

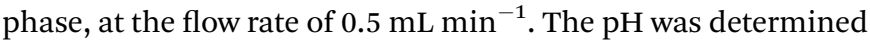
using a pH meter (pHS-3C; China). Standard analytical methods were followed to determine the content of TS and VS in the inoculum and fresh and silage feedstock. ${ }^{24}$ The fermentation material was dried in an oven at $378 \mathrm{~K}$ until constant weight was 
Table 1 Results of hydrolysis of organic particles ${ }^{a}$

\begin{tabular}{|c|c|c|c|c|c|c|}
\hline Time (d) & $\mathrm{TS} / \operatorname{mass}(\mathrm{g})$ & VS/mass (g) & $\mathrm{VS} / \mathrm{TS}$ & TWRM (g) & TS concentration $\left(\mathrm{g} \mathrm{TS} \mathrm{L}^{-1}\right)$ & VS concentration $\left(\mathrm{g}\right.$ VS $\left.\mathrm{L}^{-1}\right)$ \\
\hline 1 & 24.38 & 16.53 & 67.80 & 401.95 & 61.93 & 41.32 \\
\hline 2 & 21.33 & 13.48 & 63.20 & 405.91 & 53.63 & 33.69 \\
\hline 4 & 19.75 & 11.90 & 60.25 & 397.04 & 49.12 & 29.76 \\
\hline 7 & 19.42 & 11.57 & 59.58 & 397.71 & 48.55 & 28.92 \\
\hline 10 & 18.76 & 10.91 & 58.16 & 395.24 & 47.38 & 27.50 \\
\hline 18 & 16.98 & 9.13 & 53.77 & 382.90 & 42.48 & 22.82 \\
\hline
\end{tabular}

achieved, and then the TS content was determined. Subsequently, the raw materials were burned at $823 \mathrm{~K}$ to a constant weight in order to determine the content of VS. The VOC content was also measured using a gas chromatography-mass spectrometer (GC-MS) (Agilent 7890/5975C-GC/MS). The calorific value was determined using an automatic calorimeter (C2000, IKA, Germany).

\subsection{Kinetic models for hydrolysis}

The hydrolysis kinetic models for elephant grass were developed based on improved first-order hydrolysis models reported previously, such as flat, cylindrical, and spherical models. ${ }^{25}$

Flat model

$$
\frac{\mathrm{d} s}{\mathrm{~d} t}=-k s,
$$

Cylindrical model

$$
\frac{\mathrm{d} s}{\mathrm{~d} t}=\frac{k s^{\frac{3}{2}}}{s_{0}^{\frac{1}{2}}},
$$

Spherical model

$$
\frac{\mathrm{d} s}{\mathrm{~d} t}=-\frac{k s^{\frac{5}{3}}}{s_{0} \frac{2}{3}},
$$

where $t$ is the time (d), $s$ is the concentration of volatile organic compounds (VOCs) in the undissolved particles at time $t\left(\mathrm{~g} \mathrm{~L}^{-1}\right)$, $k$ is the total hydrolysis constant of organic particles per unit area $\left(\mathrm{d}^{-1}\right)$, and $s_{0}$ is the initial concentration of VOCs in the particles $\left(\mathrm{g} \mathrm{L}^{-1}\right)$.

\section{Results and discussion}

\subsection{Hydrolysis}

The results of hydrolysis of organic particles are presented in Table 1 . The results showed that on day 1 , the content of TS, VS, TS concentration and the ratio of VS/TS of the hydrolysate were $24.77 \mathrm{~g}, 16.53 \mathrm{~g}, 61.93 \mathrm{~g}$ TS L ${ }^{-1}$, and 66.72, respectively. With time, the organic compounds were hydrolyzed, and the content

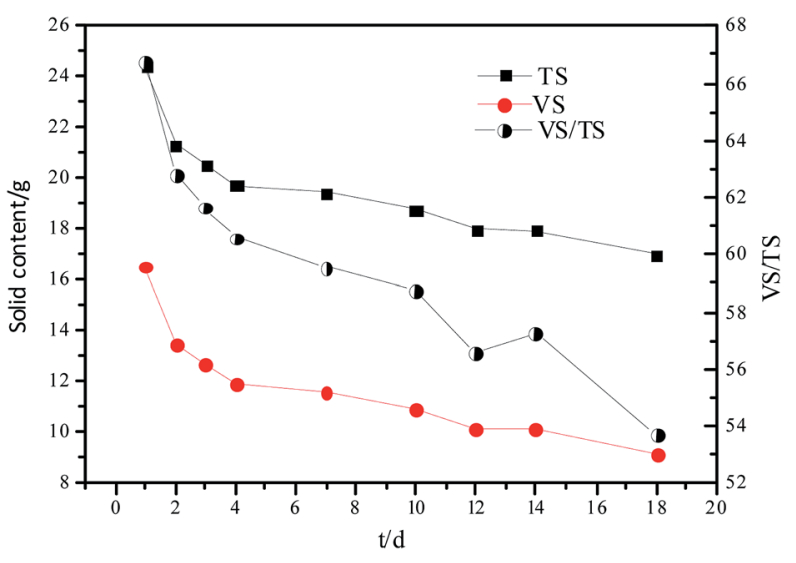

Fig. 1 Changes in TS and VS contents and VS/TS ratio of the hydrolysate with time.

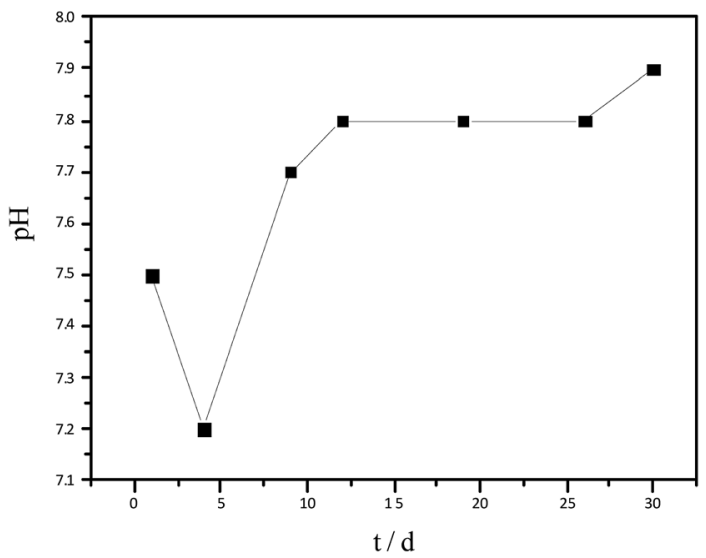

Fig. 2 Variation in $\mathrm{pH}$ of the hydrolysate with time.

of TS, VS, and TS concentration decreased to $19.42 \mathrm{~g}, 11.57 \mathrm{~g}$, and $59.58 \mathrm{~g} \mathrm{TS} \mathrm{L}^{-1}$, respectively, on day 7. In a parallel experiment, the addition of alkali or acid increased the content of TS, VS, and TS to $20.27 \mathrm{~g}, 11.81 \mathrm{~g}$, and $58.25 \mathrm{~g}$ TS $\mathrm{L}^{-1}$, respectively, on day 10 (data not shown). This indicates that the addition of alkali or acid accelerates the hydrolysis reaction.

The changes in TS and VS contents and VS/TS ratio with time are shown in Fig. 1. The hydrolytic process was faster during the 


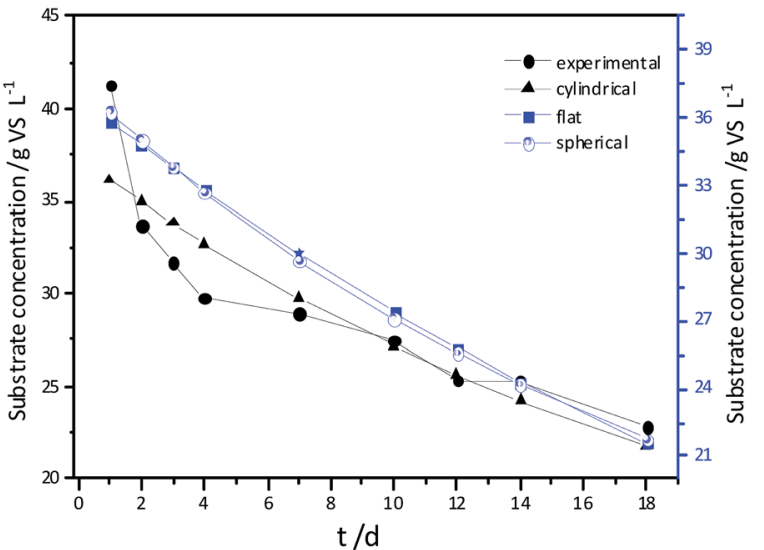

Fig. 3 Experimental results and hydrolysis constants for the flat, cylindrical and spherical models.

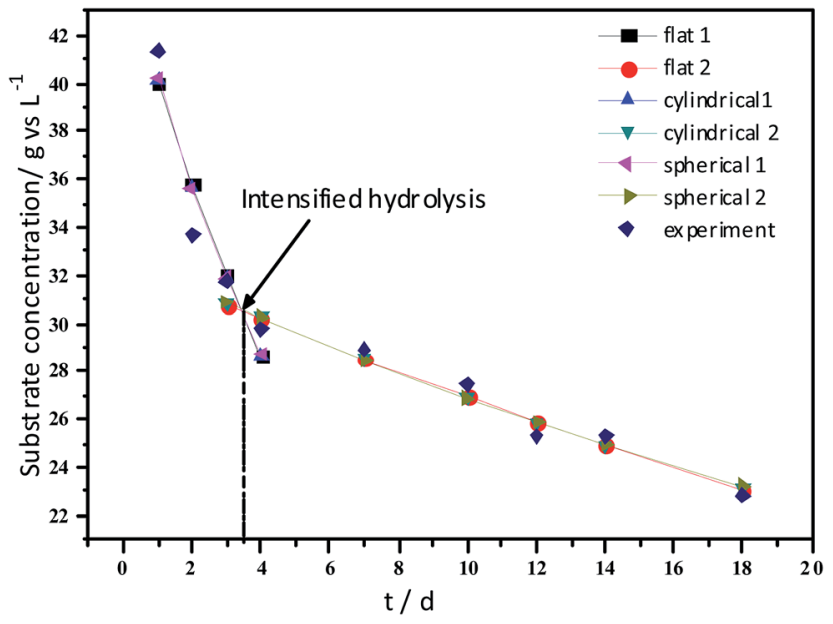

Fig. 4 Comparison of the theoretical and experimental values.

first few days owing to the rapid hydrolysis of the easily hydrolyzable organic particles, subsequently, the less biodegradable organic particles were hydrolyzed.

The variation in $\mathrm{pH}$ of hydrolysate has been shown in Fig. 2. At the beginning of hydrolysis, a slight acidification occurred,
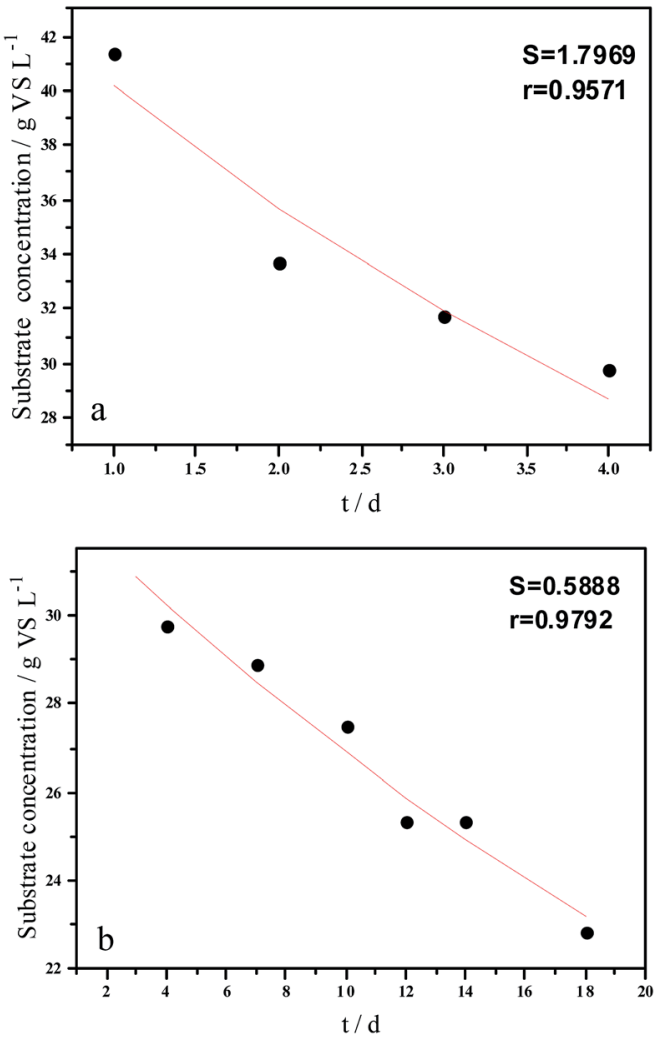

Fig. 6 Hydrolysis constants for the first (a) and second hydrolysis processes (b) for the cylindrical model.

therefore, the $\mathrm{pH}$ of the hydrolysate reduced to 7.2. With time, the production of acid was inhibited and thereby the $\mathrm{pH}$ increased again, reaching a steady value of 7.9 on day 12 . The $\mathrm{pH}$, maintained between 7.2-7.9, was within the normal range for $\mathrm{AD}$.

\subsection{Hydrolysis constants}

Experimental results and hydrolysis constants for the flat, cylindrical, and spherical models. The hydrolysis rate constants of the three models-flat, cylindrical, and spherical-were calculated according to the changes in the concentration of degradable organic particle (Fig. 3); which were $0.02947 \mathrm{~d}^{-1}(r=$ $0.8962), 0.03423 \mathrm{~d}^{-1}(r=0.9030)$, and $0.03665 \mathrm{~d}^{-1}(r=0.9072)$,
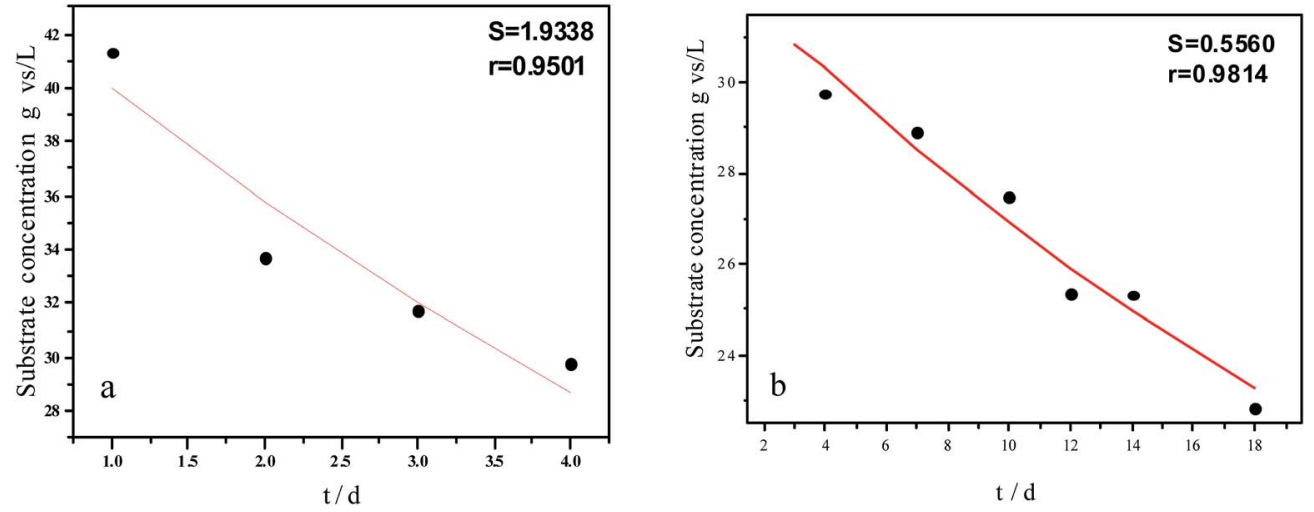

Fig. 5 Hydrolysis constants for the first (a) and second hydrolysis processes (b) for the flat model. 

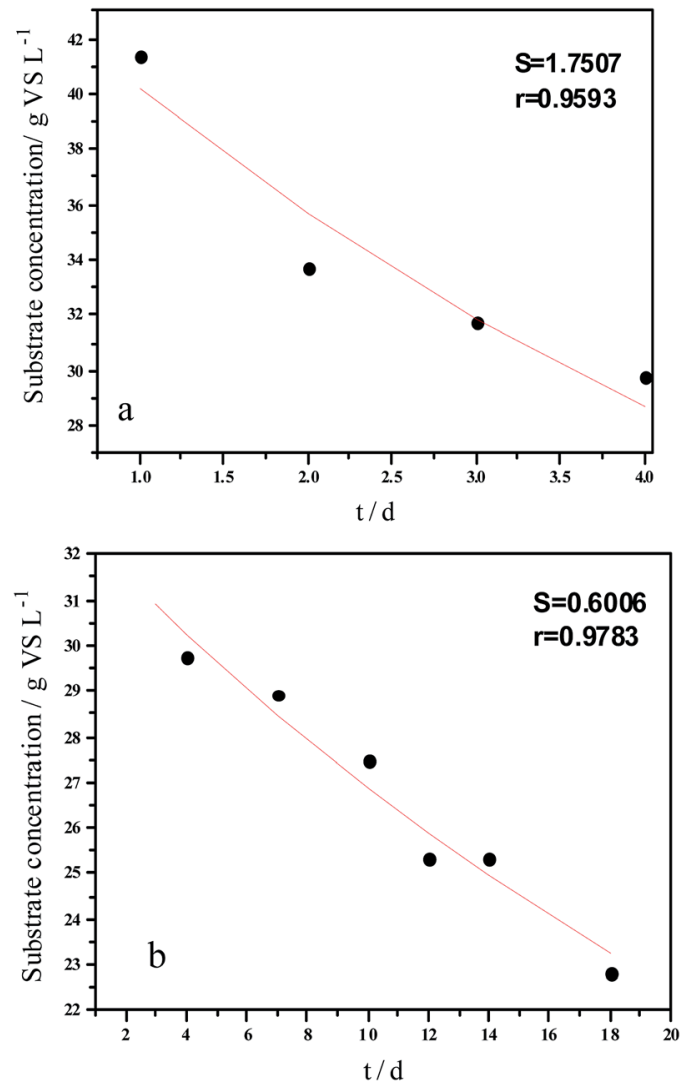

Fig. 7 Hydrolysis constants for the first (a) and second hydrolysis processes (b) for the spherical model.

respectively. The spherical model presented the best fit between the experimental and theoretical values. This demonstrates that these hydrolysis kinetic models can't effectively reveal the whole hydrolysis process of elephant grass. A deviation between the experimental and theoretical values occurred because of the disparity of hydrolysis rates in the process. There was an obvious inflection point on day 3.5 during the hydrolysis of elephant grass. This could be ascribed to that the major components of elephant grass including cellulose, hemicellulose and lignin play an important role in determining the hydrolysis rate. ${ }^{26}$ Cellulose could be hydrolyzed to glucose whereas, the hydrolysis of hemicellulose yields xylose, arabinose, glucose, mannose and galactose. Thus, the hydrolysis rate constant of oligosaccharide and some easily hydrolysable

Table 2 The hydrolysis rate constants of elephant grass for the first and second hydrolysis processes in the flat, cylindrical and spherical models ${ }^{a}$

\begin{tabular}{|c|c|c|c|c|c|}
\hline \multirow{2}{*}{\multicolumn{2}{|c|}{ Hydrolysis parameter }} & & \multicolumn{3}{|l|}{ Models } \\
\hline & & & Flat model & Cylindrical model & Spherical model \\
\hline \multirow[t]{2}{*}{ Before $3.5 \mathrm{~d}$} & Hydrolysis constant $\left(\mathrm{d}^{-1}\right)$ & $k_{1}$ & 0.1111 & 0.1300 & 0.1376 \\
\hline & & $r$ & 0.9501 & 0.9571 & 0.9593 \\
\hline \multirow[t]{2}{*}{ After $3.5 \mathrm{~d}$} & Hydrolysis constant $\left(\mathrm{d}^{-1}\right)$ & $k_{2}$ & 0.0191 & 0.0211 & 0.02183 \\
\hline & & $r$ & 0.9814 & 0.9792 & 0.9783 \\
\hline
\end{tabular}

${ }^{a} k_{1}$ and $k_{2}$ are the first and second hydrolysis rate constants, respectively. $r$ is the correlation coefficient. hemicellulose of elephant grass was high, while that of cellulose and hardly hydrolyzable hemicellulose was low. However, it is almost impossible to hydrolyze lignin. Therefore, in order to reflect the reaction process more accurately, the hydrolysis process was attempted to be modeled by a two-step approach with piecewise fitting using the three models (Fig. 4-7); the two steps were denoted as the first and second hydrolyses.

The experimental results and hydrolysis rate constants obtained using the theoretical models for elephant grass showed the following: first, the theoretical values exhibited a good curve-fit (the expected values were similar to the experimental values). Second, the first and second hydrolysis rate constants can be obtained by notable inflection of the hydrolysis rate constants on day 3.5. Before $3.5 \mathrm{~d}$, the hydrolysis rate constant was high because of the rapid hydrolysis of the easily hydrolysable organic particles, such as oligosaccharide and some easily hydrolyzable hemicellulose, thus, the VS concentration decreased significantly during this period. Subsequently, the cellulose and hardly hydrolyzable hemicellulose began to be hydrolyzed and hence the hydrolysis rate decreased after $3.5 \mathrm{~d}$, therefore, the decreasing trend of VS concentration became slower. From Table 1, a conclusion can be obtained that, $3.5 \mathrm{~d}$ before hydrolysis, the degradation ratio of the VS reached $27.89 \%$, which was $62.30 \%$ that of the whole hydrolysis process. After $3.5 \mathrm{~d}$, the hydrolysis rate dropped with the accumulation of hardly degradable organics, such as lignin. Therefore, the intersection of the two stages due to the disparity of hydrolysis rates in the process can be considered as the secondary reinforcement (intensified hydrolysis) point for elephant grass hydrolysis. Measures such as the addition of alkali or acid to the solid of the fermentation can be taken at this point to accelerate the hydrolysis process, this will be evaluated by us in the future. The hydrolysis rate constants of elephant grass for the first and second hydrolysis processes can be calculated from the three models (Fig. 5-7) as shown in Table 2. According to the results calculated from the spherical model, the hydrolysis rate constant of elephant grass was fast as much as $0.1376 \mathrm{~d}^{-1}$ before $3.5 \mathrm{~d}$ and thereafter reduced to $0.02183 \mathrm{~d}^{-1}$.

\section{Conclusions}

In the present study, the hydrolysis dynamics of elephant grass was investigated by a two-step approach. Three models were used to fit the hydrolysis rate constants-flat, spherical, and cylindrical models. The curve fits of the three models for 
elephant grass hydrolysis dynamics to the measured data suggested that the spherical model was the optimal one with the first and second hydrolysis rate constants of $0.1376(r=0.9593)$ and $0.02183(r=0.9783)$, respectively. In addition, the secondary reinforcement point for the hydrolysis of elephant grass $(3.5 \mathrm{~d}$ ) caused by a disparity of hydrolysis rates in the process was also determined to accelerate the hydrolysis process, this might play an important role in accelerating the hydrolysis of elephant grass. The findings of the present study might form the basis for the AD of energy grasses, especially elephant grass. Furthermore, the findings might benefit studies on elephant grass hydrolysis process, thus promoting its application in biogas industry as an alternative biofuel.

\section{Conflicts of interest}

There are no conflicts to declare.

\section{Acknowledgements}

The study was supported by the National Key Research and Development Program of China (2017FYD0800801); Bureau of International Cooperation, Chinese Academy of Sciences (182344KYSB20170009); Science and Technology Planning Project of Guangdong Province (2017A050501049, 2017B020238002); Natural Science Foundation of Guangdong (2017A030310280) and Science and Technology Program of Guangzhou (201707010201).

\section{References}

1 G. Zhen, X. Lu, T. Kobayashi, Y.-Y. Li, K. Xu and Y. Zhao, Appl. Energy, 2015, 148, 78-86.

2 M. Pérez-Boada, A. Prieto, P. Prinsen, M.-P. Forquin-Gomez, J. C. del Río, A. Gutiérrez, Á. T. Martínez and C. B. Faulds, Bioresour. Technol., 2014, 167, 469-475.

3 P. Prinsen, A. Gutiérrez and J. C. del Río, J. Agric. Food Chem., 2012, 60, 6408-6417.

4 D. Pimentel and T. W. Patzek, Nat. Resour. Res., 2005, 14, 6576.

5 T. Březinová and J. Vymazal, Ecol. Eng., 2015, 80, 62-68.

6 X. Zhao, L. Zhang and D. Liu, Biotechnol. J., 2010, 5, 493-504.

7 C. Somerville, H. Youngs, C. Taylor, S. C. Davis and S. P. Long, Science, 2010, 329, 790-792.
8 R. A. Flores, S. Urquiaga, B. J. R. Alves, L. S. Collier and R. M. Boddey, Eng. Agric., 2012, 32, 831-839.

9 R. Saikia, B. Baruah, D. Kalita, K. K. Pant, N. Gogoi and R. Kataki, Bioresour. Technol., 2018, 253, 304-314.

10 M. Zeng, E. Ximenes, M. R. Ladisch, N. S. Mosier, W. Vermerris, C. P. Huang and D. M. Sherman, Biotechnol. Bioeng., 2012, 109, 390-397.

11 G. Koçar and N. Civaş, Renewable Sustainable Energy Rev., 2013, 28, 900-916.

12 M. P. Robbins, G. Evans, J. Valentine, I. S. Donnison and G. G. Allison, Prog. Energy Combust. Sci., 2012, 38, 138-155.

13 F. Cattaneo, P. Di Gennaro, L. Barbanti, C. Giovannini, M. Labra, B. Moreno, E. Benitez and C. Marzadori, Appl. Soil Ecol., 2014, 84, 213-222.

14 L. Lianhua, Z. Feng, S. Yongming, Y. Zhenhong, K. Xiaoying, Z. Xianyou and N. Hongzhi, Bioresour. Technol., 2014, 173, 439-442.

15 N. T. Xuyen, D. P. V. Sanchez, T. H. Kim, H. Il Park, M. Yun and Y. H. Lee, J. Mater. Chem., 2010, 20, 5468-5473.

16 G. Yang and J. Wang, Bioresour. Technol., 2018, 255, 7-15.

17 R. Borja, A. Martin, E. Sanchez, B. Rincón and F. Raposo, Process Biochem., 2005, 40, 1841-1847.

18 A. Valentini, G. Garuti, A. Rozzi and A. Tilche, Water Sci. Technol., 1997, 36, 239-246.

19 W. Hu, K. Thayanithy and C. Forster, Process Biochem., 2002, 37, 965-971.

20 V. A. Vavilin, S. V. Rytov and L. Y. Lokshina, Bioresour. Technol., 1996, 56, 229-237.

21 B. E. Rotter, D. A. Barry, J. I. Gerhard and J. S. Small, Bioresour. Technol., 2008, 99, 5738-5748.

22 P. Biernacki, S. Steinigeweg, A. Borchert and F. Uhlenhut, Bioresour. Technol., 2013, 127, 188-194.

23 A. Sluiter, B. Hames, R. Ruiz, C. Scarlata, J. Sluiter, D. Templeton and D. Crocker, Technical Report NREL, 2008, TP-510-42618.

24 APHA, Standard Methods for the Examination of Water and Wastewater, American Public Health Association, DC, USA, 18 th edn, 1998.

25 L. Guotao, P. Xuya, L. Tengrui, J. Chuanxin, W. Xiang and C. Zhijian, Acta Sci. Circumstantiae, 2007, 27, 1227-1232.

26 W. Prapinagsorn, S. Sittijunda and A. Reungsang, Energies, 2017, 10, 1654. 